\title{
TOURIST PROFILE OF YOUNG-ADULTS IN MACEDONIA AND THEIR PERCEPTION OF E-TOOLS
}

PhD Biljana Petrevska, Assistant Professor, Faculty of Tourism and Business Logistics, Goce Delcev" University - Stip, Macedonia, e-mail: biljana.petrevska@ugd.edu.mk

\begin{abstract}
The paper intends to create a tourist profile of young-adult consumers as well as to examine their attitude towards e-tools. More precisely, the study examines how young people percept the Internet as rapidly evolving medium, and do they use the on-line social networks (OSN) in sharing experiences. In both cases, the main research area is tourism and travel. So, the aim and objective of the paper are to determine a tourist profile among young population in Macedonia and simultaneously to determine the level of application of e-tools. For this purpose, a survey was conducted among undergraduate students. The results point to interesting conclusions regarding travel habits and interests, planning activities, type of accommodation, preferences and other data that support the created tourist profile. With regards to research hypotheses, the outcomes confirm solid causality between tested variables concluding that young population in Macedonia use e-tools for travel and tourism purposes. Such findings one may find useful for tailoring strategies to the specific characteristics and initially created tourist profile of young consumers in Macedonia.
\end{abstract}

Key words: Tourist profile; Young-adults; Internet; OSN; Tourism.

\section{Introduction}

There is an inevitable relationship between tourism and information. Moreover, it is a widely-recognized the fact that information and decision-making have become the foundation for the world economy (Wang, 2008).In the other side, bigger number of tourists and travelers also means potential source for strengthening the national economy. However that is not a trouble-free process, particularly in turbulent environment. Moreover, by mediation of digital environment, it is noticeable the obvious tourists' transformation from"passive audiences" to "active players" (Prahalad and Ramaswamy, 2000). A noteworthy change was made from just passive searching and surfing to creating content, collaborating and connecting. Hence, the development of the Internet and the on-line social networks (OSN) empowered the "new" tourists who became knowledgeable and ask exceptional value for their money and time (Buhalis and Law, 2008).

Whether a potential tourist will be interested in a certain item depends on the preferences. Although may sound fragile, but the vast majority of today's tourists know exactly what they are looking for. They are very demanding and have complex, multi-layered desires and needs. Today's so called "postmodern tourists" have specific interests and individual motives which results in tailored made tourist products according to their particular preferences. They are often high experienced in travelling and demand perfect tourism products rather than standardized ones.

In this line, each generation has a different motivation for travel and tourism. The seniors want to be active, feel useful, and meet with other people to gain new friends (Ekerdt, 1986). The young people want to gain new skills, to be part of the community and to enjoy life. Being ICT literate, they use the technology for various purposes. So, in Macedonia $92.1 \%$ of computer users aged 15-24 years, are registered that have ever used a computer. Among them, $89.0 \%$ are Internet users with high and exceptional frequency of $86.0 \%$ of Internet usage on daily basis. Furthermore, from all activities on the Internet (like: e-correspondence; telephoning; reading or downloading online news; finding information about goods or services; listening/watching radio/TV; playing or downloading games, images; Internet banking etc.), $89.7 \%$ goes on posting messages to chat sites, OSN, Page | 49 
blogs, newsgroups or online discussion forum and use of instant messaging. Among all user groups aged between 1574 , the group consisted of young population between 15-24 years use the most mobile phones or smartphones representing $77.8 \%$. They even access the Internet away from home via mobile phones or smartphones in $28.1 \%$ (State Statistical Office, 2012: 5-6). So, it is easy to conclude that Facebook, MySpace, Twitter, Friendster, Bebo or some other OSN supported by mobile device are among favorite things the youngsters in Macedonia are addicted to. Generally, to this conclusion one may add regional or even world approach.

This study, specifically intends to answer the following research questions, which address the young-adult tourism consumers in Macedonia:

1. What are their travel and tourism preferences, interests, needs and expectations?

2. Do they use the Internet and OSN for travel and tourism purposes?

3. Do they share travel and tourism experiences by e-media?

In order the meet the research questions, the paper is structured in several parts. After the introductory part, Section two makes a brief overview on some relevant literature referring e-tools and their application in tourism purposes. Section three incorporates the methodology and research design. The results, analyses, discussion and evaluation are noted in section four. Section five includes conclusions and future research directions.

Generally, the contribution of this paper lies in the fact that makes an attempt to create a tourist profile of young-adults which may be used for tailoring a tourismsegmented strategy for young consumers in Macedonia. Additionally, it presents some interesting findings regarding their perception of e-tools and their application in travel and tourism purposes.
2. Literature review on Internet, OSN and search engines in tourism

In very short time, the Internet was introduced as a rapidly evolving medium for travel and tourism. It successful introduction to e-tourism is fully supported by the search engines which became a dominant source in tourists' use to access particular tourism and travel products (Schonland and Williams, 1996). In this respect, the OSN gain in significance as well. It is known that social networking is a platform, or a site that focuses on building and reflecting of social networks or social relations among people, who have similar or somewhat similar interests, backgrounds or activities and share them simultaneously. Although social networking is possible in person, it is most popular on-line by application of the websites. As the increase in popularity of the OSN is on constant rise, the OSN find its application in travel and tourism purposes. It is often a case to be used for sharing travel and tourism information and experience with one another.

Due to its significance, the issue of etools and their application in tourism domain raised an interest within academia. Generally, they argue regarding the understanding how search engines work and how travelers use the Internet and booking systems as tools in e-tourism (Morrison et al., 2001; Singh and Kasavana, 2005; Connolly and Lee, 2006; Pan et al., 2007; Buhalis and Law, 2008; Pan et al., 2011; Xiang and Pan, 2010). Moreover, the success of search engine marketing requires a good understanding of consumer behavior in order to provide the information desired by different consumers. Furthermore, the necessity of developing digital technology that will support the personalized services to address individual needs is fully justified. Tourism actors should collect customer information before, during and after a visit in order to better understand consumer behavior choices and determinants 
(Buhalis and O'Connor, 2005). Additional insights regarding the progress of IT in tourism domain is noted in many research findings (Kluge, 1996; Kirk and Pine, 1998; Frew, 2000; O’Connor and Murphy, 2004; Leung and Law, 2005 and 2007; Law et al., 2009).

Some researches address different approaches dealing with variety of relationships that appeared in e-tourism. So, Weber and Roehl (1999) explored demographics between Internet users and tourists at the same time. However, little research has been done on the travelrelated behaviors of Internet travelers. In this respect, Morrison et al. (2001) found that some book travel on-line, while others go to travel agents or call the toll-free numbers of travel providers after getting travel information on-line. With regards to the behavioral dimensions, it may be utilized to segment travel markets as a powerful tool in managing e-tourism (Hennessey et al., 2008). Regardless the approach, it must be underlined that tourism needed this kind of information some years ago, while today we are faced with tourists with different travel patterns which cause different activity while travelling.

\section{Methodology and research design}

The study mainly took a quantitative approach to answer the research questions noted in the introductory part. The data were collected by a self-administered questionnaire survey in three locations in Macedonia: Skopje, Stip and Gevgelija. The survey was conducted during March 2012 among undergraduate students in tourism studies. They were previously well informed about the survey's aims in order to avoid any attempt to manipulate the survey process and possibly bias the results. Since young people are eager to consume, as well as are conscious of their experience, they are valid consumers for this study (Sproles and Kendall, 1986).

The structured questionnaire consisted of three sections. Section 1 contained demographic attributes of the respondents. Section 2 was consisted of fifteen items pointing to travel and tourism preferences, attitudes, desires and motives towards various points. Section 3 contained ten items measuring the application of e-tools. A total of 520 copies of the questionnaire were distributed, out of which 502 were deemed complete and usable, thus having response rate of $97 \%$. The collected data were transferred to a common scorecard database in SPSS 20.0. Some descriptive statistics and nonparametric statistical tests were used for creating an initial tourist profile among young-adults. The research hypotheses were tested by $\chi^{2}$ - test.

\subsection{Creating a tourist profile}

For the purpose of creating a tourist profile of young respondents, the data gathered by Section 1 and Section 2 were acquisitioned. In order to assess respondent's ratings the Likert scale and the semantic different scale were applied. So, the respondents had to choose a rating for the items from Section 2 on a adopted 4-point Likert scale, whereas $1=$ poor, 2=average, 3=good and 4=very good. Simultaneously, the satisfaction perceived by the respondents was measured by a 4point semantic different scale, whereas $1=$ far below ideal, $2=$ very close to ideal, $3=$ better than expected and 4=very satisfied. 
Table 1.Demographic profile of respondents $(n=502)$

\begin{tabular}{|c|c|c|}
\hline Characteristic & $\begin{array}{c}\text { Valid } \\
n\end{array}$ & $\%$ \\
\hline \multicolumn{3}{|l|}{ Gender } \\
\hline Male & 246 & 49.0 \\
\hline Female & 256 & 51.0 \\
\hline \multicolumn{3}{|l|}{ Age } \\
\hline$<30$ & 484 & 96.4 \\
\hline$>30$ & 18 & 3.6 \\
\hline \multicolumn{3}{|l|}{ Place of living } \\
\hline Town & 404 & 80.5 \\
\hline Village & 98 & 19.5 \\
\hline \multicolumn{3}{|l|}{ Geographical area } \\
\hline Skopje & 103 & 20.5 \\
\hline North-East & 26 & 5.2 \\
\hline East & 210 & 41.8 \\
\hline South-East & 137 & 27.3 \\
\hline Vardar & 10 & 2.0 \\
\hline Pelagonija & 4 & 0.8 \\
\hline South-West & 7 & 2.8 \\
\hline Polog & 5 & 1.0 \\
\hline \multicolumn{3}{|l|}{ Marital status } \\
\hline Married & 30 & 6.0 \\
\hline Single & 472 & 94.0 \\
\hline \multicolumn{3}{|l|}{ Working status } \\
\hline Employed & 35 & 7.0 \\
\hline Unemployed & 467 & 93.0 \\
\hline \multicolumn{3}{|c|}{ Monthly household income $(€)$} \\
\hline$\leq 250$ & 133 & 26.5 \\
\hline $250-300$ & 242 & 48.2 \\
\hline$>300$ & 127 & 25.3 \\
\hline
\end{tabular}

Table 1 presents the demographic attributes regarding: gender, age, place of living, geographical area, marital and working status, as well as monthly household income. It is noticeable almost ideal gender equality among respondents, whereas the vast majority is under 30 years of age. Furthermore, majority live in urban areas $(81 \%)$, being single $(94 \%)$ and generally come from three (out of eight) geographic regions in Macedonia (Skopje $21 \%$, East - $41 \%$ and South-East - 27\%). Since the sample is consisted of university students, it is expected to be unemployed (93\%). The monthly household income is between $€ 250-300$ (48\%) presenting an average salary in Macedonia.
With regards to questions that refer to frequency of making a holiday, duration of stay, companionship, planning activities, type of transport and accommodation, the profiling is as follows:

- Travels once per year with a duration of 5-10 days;

- Travels in a group of 3-5 persons, very rarely with family members;

- Aim of travel: fun;

- Always travels in season (summer);

- Travels by car, generally within Macedonia, and sometimes in neighboring countries;

- Always plans the holiday one week in advance;

- Type of accommodation: hotel with 3 stars or private accommodation - BB. 
With regards to questions that refer to type of holiday, level of consumption, sources of financing, methods of payment and level of satisfaction with services, the profiling is as follows:

- Likes active holiday;

- Spends on additional tourism consumption between $€ 100-300$, mostly on food and fun;

- The price is the main factor for making decision for travel and tourism;

- Very rarely, almost never uses a tourist guide;

- The holiday is paid by others (parents or partners);

- Always pays in cash for services;

- In case of being unsatisfied with the services, almost never undertakes measures and actions.

\subsection{Research hypotheses}

Based on research questions stated in the introductory part, the study intends to reach the following objectives: (a) to gain an in-depth understanding of application of Internet among young-adult consumers in Macedonia, and (b) to empirically tests the application of the OSN in tourism and travel purposes and sharing experiences.

Hence, the following hypotheses are proposed:

Q1: Young-adults use Internet for travel and tourism purposes.

Q2: Young-adults apply OSN for sharing travel and tourism experiences.

4. Results, analysis, discussion and evaluation

As noted previously, for testing the research hypothesis we applied the $\chi^{2}$ - test to test the association between the variables. Since, the significance level was set at $5 \%$, the variables whose mean value was $>0.05$ were considered under relation oriented.

Table 2.Test of hypotheses $(n=502)$

\begin{tabular}{|c|c|c|c|}
\hline \multicolumn{4}{|c|}{ Q1 } \\
\hline & Value & Degree of freedom & p-value \\
\hline Pearson $\chi^{2}$ & 6.752 & 2 & .034 \\
\hline Likelihood Ratio & 6.939 & 2 & .031 \\
\hline Linear-by-Linear Association & 6.223 & 1 & .013 \\
\hline \multicolumn{4}{|c|}{ Q2 } \\
\hline & Value & Degree of freedom & p-value \\
\hline Pearson $\chi^{2}$ & 18.099 & 9 & .004 \\
\hline Likelihood Ratio & 21.623 & 9 & .010 \\
\hline Linear-by-Linear Association & 9.771 & 1 & .002 \\
\hline
\end{tabular}

In this line, we test both research hypotheses. Namely, the tests for Q1 refer to association between travel and tourism needs and the Internet among the youngadults in Macedonia. The tests for Q2 are in line of detecting whether there exists relationship between the OSN and sharing travel and tourism experience among young population in Macedonia. The results are presented in Table 2. The research indicated positive effects for both hypotheses i.e. substantial results since the Pearson $\chi^{2}$ value for Q1 is 0.034 and for Q2 is 0.004 . In both cases the values are less than the significance level. Further data presented in Table 2 additionally support the significant outcomes towards Q1 and Q2, thus confirming solid causality between the variables.

The next step is the evaluation of the research. Different tests may be applied to reinsure the research results. Among the variety of concepts, the reliability and validity of data (Yin, 1994) are introduced in addition. The reliability is regularity and soundness of a tool used for measurement 
of data. It shows how much reliable is the measurement which has been adopted to measure the collected data. More precisely, the reliability tells if the repeated replications research happens the same results would be achieved. It explains how far away the approaches yield the same conclusion. The concept of validity is used for the measurement of quantitative data. It is described as to what extend the conclusion can reflect the accurate conclusion, leading to conclusion that the findings are valid and trustworthy. Moreover, the validity is degree to which adopted measurement tools may be helpful to measure the asked questions.

Furthermore, we introduce the Cronbach $\alpha$ coefficient as a coefficient of reliability. It is commonly used for measuring internal consistency or reliability of a psychometric test score for a sample of examinees. The results indicated Cronbach $\alpha$ for questionnaire (502 items) was 0.901 representing excellent internal consistency. Furthermore, the results pointed from good to acceptable internal consistency. So, the Cronbach $\alpha$ for individual variable of perceived fit was (0.857); perceived usage (0.821) and sharing experiences (0.794).

\section{Conclusion and future work}

This study investigated the initial tourist profiling of young population and their attitude towards application of e-tools in tourism and travel purposes. In this respect, besides creating a tourist profile of a typical young tourist and traveler of Macedonia, two additional aspects were particularly addressed: the perception of Internet as an e-medium for travel and tourism, and the application of OSN in sharing travel and tourism experiences.

A survey was conducted on a sampling consisted of undergraduate students as representatives of young population. The outcomes from the profiling process confirmed some already known facts but posed some new as well.
Namely, the fact that youngsters spend 510 days on holiday, which is bigger than the average stay of domestic tourists in Macedonia (4.8 days) implies that this group should be considered as serious potential consumers. Since their main aim of travel is fun, one may argue the necessity of enhancing this kind of facilities that are in favor of supporting active holiday. Interesting, but not surprising is the fact that young-adults prefer to travel in small groups up to five persons who are not family members. As the student vacation is in summer, normally they use it as a main travel and tourism season. The modest travel budget, limits them to travel within the country or to neighboring countries the farthest, being accommodated in three-star hotels with BB service. Yet, surprising is the finding that although being juniors, they always plan their holiday one week in advance, which points to a preference to reduce the risk for unpleasant surprise. Due to fact of being unemployed category (since the respondents were students), they are categorized as consumers with low consumption power whereas the price is the main factor for making travel decisions. Generally, their parents or partners are the main source of financing. Obviously they are not very responsible with money spending, since always pay in cash for services and not use credit-cards. The finding that they almost never use a tourist guide underlines the necessity of undertaking measures for advanced informing about the important role that tourist guides play in travel and tourism process. Although being full with energy, the data showed that in cases when not being satisfied with the services, they never undertake measures and actions.

Another aspect of this paper was to find out whether young population in Macedonia is keen on applying CT for travel and tourism. Through statistical analysis it was identified that generally, they use the Internet as a basic source for travel and tourism information. The vast 
majority of respondents has a profile page on the OSN and uses it for sharing travel and tourism experiences. So, the young population in Macedonia identified the OSN as a cradle for sharing info from their trip and holiday.

Furthermore, the study was limited by several factors that may be addressed in some future research. Because only crosssectional data were collected through a questionnaire survey, the study may suffer from common method variance effect. The sample size was also not big enough to verify the factor structures. Namely, the analysis took a snapshot of a selected sample in Macedonia referring university students who have generally limited travel and tourism experience. Moreover, the results address $90 \%$ of respondents coming only from three geographical areas (Skopje, East and South-East). To gain a better overview of this research area, future studies may expand the sample to include young population from other statistical planning regions in Macedonia in more equal manner. Thus, it may not be possible to generalize the results to whole young population in Macedonia. As this research represents a relatively small sample size, future work may also focus on extending the number of respondents and other aspects of investigation. Despite these limitations, the study is reach on useful findings and poses some valuable directions for further research.

\section{References}

1.Buhalis, D. \& Law, R. (2008). Progress in information technology and tourism management: 20 years on and 10 years after the Internet - the state of eTourism research.Tourism Management, 29,609-623.

2.Buhalis, D. \& O’Connor, P. (2005). Information Communication Technology Revolutionizing Tourism. Tourism Recreation Research, 30(3), 7-16.

3.Connolly, D. J., \& Lee, S. (2006). Developing information technology proficiencies and fluency in hospitality students.Journal of Hospitality \&Tourism Education, 18(3), 15-29.
4.Ekerdt, D. (1986). The Busy Ethic Moral Continuity Between Work \& Retirement. The Gerontologist, 6(3), 239-244.

5.Frew, A. J. (2000). A critical analysis of tourisminformation technology research. In D. R.Fesenmaier, S. Klein, \& D. Buhalis (Eds.),Information and communication technologies intourism (pp. 39-52). New York: Springer-Verlag.

6.Hennessey, S. M., MacDonald, R. \& MacEachern, M. (2008). A Framework for Understanding Golfing Visitors to a Destination. Journal of Sport \& Tourism. 13(1), 5-35.

7.Kirk, D., \& Pine, R. (1998). Research in hospitalitysystems and technology. International Journal ofHospitality Management, 17(2), 203-217.

8.Kluge, E. A. (1996). A literature review of informationtechnology in the hospitality curriculum.Hospitality ResearchJournal, 19(4), 4564.

9.Law, R., Leung, R. \& Buhalis, D. (2009). Information technology application in hospitality and tourism: a review of publications from 2005 to 2007. Journal of Travel and Tourism Marketing, 26: 5-6, 599-623.

10. Leung, R., \& Law, R. (2005). An analysis ofinformation technology publications in leadinghospitality journals. FIU Hospitality Review,23(2), 55-65.

11. Leung, R., \& Law, R. (2007). Information technologypublications in leading tourism journals: A studyof 1985 to 2004. Information Technology \&Tourism, 9(2), 133-144.

12. Morrison, A., Su, J., O'Leary, J.\&Cai, L. (2001). Predicting usage of the Internet for travel bookings: An exploratory study. Information Technology and Tourism, 4(1), 15-30.

13. O'Connor, P., \& Murphy, J. (2004). Research oninformation technology in the hospitality industry.International Journal of HospitalityManagement, 23(5), 473-484.

14. Pan, B., Litvin, S.W.\& O’Donnell, T. E. (2007). Understanding accommodation search query formulation: The first step in putting 'heads in beds'. Journal of Vacation Marketing, 13(4), 371-381.

15. Pan, B., Xiang, Z., Fesenmaier, D. R. \& Law, R. (2011). The dynamics of search engine marketing for tourist destinations. Journal of Travel Research,50(4), 365-377.

16. Prahalad, C. K. \& Ramaswamy, V. (2000).Co-opting Customer Competence.Harvard Business Review, 78(1), 7987.

17. Schonland, A. M. \& Williams, P. W. (1996).Using the Internet for Travel and Tourism Survey Research: Experiences from the Net Traveler Survey.Journal of Travel Research, 35(2), 81-87. 
18. Singh, A. J. \& Kasavana, M. L. (2005). The impact of information technology on future management of lodging operations: A Delphi study to predict key technological events in 2007 and 2027. Tourism \& Hospitality Research, 6(1), 24-37.

19. Sproles, G. B. \& Kendall, E. L., (1986).A methodology for profiling consumer decisionmaking styles.The Journal of Consumer Affairs, 20(2), 67-79.

20. State Statistical Office of the Republic of Macedonia (2012). News Release: Usage of information and communication technologies in households and by individuals, 2012. Year L, No. 8.1.12.28.
21. Wang, J. (2008). Improving decision-making practices through information filtering. International Journal of Information and Decision Sciences, 1(1), 1-4.

22. Weber, K. \& Roehl, W. S. (1999).Profiling People Searching for and Purchasing Travel Products on the World Wide Web. Journal of Travel Research, 37(3), 291-298.

23. Xiang, Z. \& Pan, B. (2010). Travel queries on cities in the United States: Implications for search engine marketing for tourist destinations. Tourism Management, 32(1), 88-97.

24. Yin, R. (1994).Case study research: Design and methods. Beverly Hills, CA: Sage Publishing. 